\title{
CrystEngComm
}

Cite this: CrystEngComm, 2014, 16 3312

Received 28th December 2013, Accepted 27th January 2014

DOI: $10.1039 / c 3 c e 42645 a$

www.rsc.org/crystengcomm

\section{Csl: $\mathrm{Tl}^{+}, \mathrm{Yb}^{2+}:$ ultra-high light yield scintillator with reduced afterglow $\dagger$}

\author{
Yuntao Wu, ${ }^{\text {a }}$ Guohao Ren, ${ }^{\text {*a }}$ Martin Nikl, ${ }^{\mathrm{b}}$ Xiaofeng Chen, ${ }^{a}$ Dongzhou Ding, ${ }^{a}$ \\ Huanyin $\mathrm{Li}^{\mathrm{a}}{ }^{\mathrm{a}}$ Shangke Pan ${ }^{\mathrm{a}}$ and Fan Yang ${ }^{\mathrm{C}}$
}

\begin{abstract}
The afterglow problem has been preventing Csl:TI single crystal scintillators from being used for applications in the field of computer tomography and high-speed imaging. We show that $\mathrm{Yb}^{2+}$ codoping in Csl:Tl can reduce it at least by one order of magnitude after $50 \mathrm{~ms}$ from X-ray cut-off compared to ordinary Csl:Tl. After optimization of the $\mathrm{Yb}^{2+}$ and $\mathrm{Tl}^{+}$concentrations, the doubly doped Csl:Tl,Yb crystal exhibits an ultra-high light yield of $90000 \pm 6000$ photons $\mathrm{MeV}^{-1}$, energy resolution $7.9 \%$ @511 keV and low afterglow level of about $0.035 \%$ at 80 ms. Simultaneous improvement in afterglow, light yield and energy resolution in Csl:Tl-based scintillators paves the way to its application in computer tomography and high-speed imaging. The physical mechanism and role of ytterbium ions in afterglow suppression are proposed
\end{abstract}

Tl-doped cesium iodide was introduced in 1951 as one of the first single crystal scintillators. ${ }^{1}$ It shows a high light yield 66000 photons $\mathrm{MeV}^{-1}$, scintillation response dominated by $800-1000 \mathrm{~ns}$ decay time and an emission band at $550 \mathrm{~nm}$ matching well the semiconductor photodetector sensitivity range. ${ }^{2}$ Furthermore, it has medium density $\left(4.53 \mathrm{~g} \mathrm{~cm}^{-3}\right)$ and higher effective atomic number $\left(Z_{\text {eff }}=54\right)$ and allows the fabrication of micro-columnar films. Given its low cost, CsI:Tl materials became widely used for radiological imaging, ${ }^{3}$ $\mathrm{X}$-ray and gamma ray spectroscopy, homeland security and nuclear medicine applications. However, due to the persistent afterglow in CsI:Tl attributed to thermal ionization of trapped electrons $\left(\mathrm{Tl}_{0}\right)$ followed by radiative recombination with trapped holes $\left[V_{\mathrm{KA}}\left(\mathrm{Tl}^{+}\right)\right],{ }^{4}$ which causes the pulse pile up in high count-rate applications, its usage in computer tomography (CT) and high-speed imaging applications is thus not possible. .,6 $^{2}$ Thus, ways to suppress the afterglow in CsI:Tl have been researched intensively over the last two decades.

In general, co-doping by an appropriate ion was found to be an effective method to suppress the afterglow in scintillators and phosphors as has been shown e.g. in $\mathrm{Gd}_{2} \mathrm{O}_{2} \mathrm{~S}$-based

\footnotetext{
${ }^{a}$ Shanghai Institute of Ceramics, Chinese Academy of Sciences, No. 215 Road, Jiading District, Shanghai, 201899, PR China. E-mail: caswyt@hotmail.com, rgh@mail.sic.ac.cn; Fax: +86 21 59927184; Tel: 862169987745

${ }^{b}$ Institute of Physics, Academy of Sciences of the Czech Republic, Cukrovarnická 10, 16253 Prague 6, Czech Republic

${ }^{c}$ California Institute of Technology, Pasadena, CA 91125, USA

$\dagger$ Electronic supplementary information (ESI) available: Optical absorption spectra and X-ray excited luminescence spectra data for CsI:Tl group A crystals. Pulse height spectra data for CsI:Tl group A crystals, when excited with a 137Cs source. See DOI: 10.1039/c3ce42645a
}

or $(\mathrm{Y}, \mathrm{Gd})_{2} \mathrm{O}_{3}$-based phosphors and optical ceramics, see ref. 2 and the references therein. The afterglow in $\mathrm{Lu}_{2} \mathrm{SiO}_{5}$ :Ce (LSO:Ce) scintillator was soon recognized as a serious limitation ${ }^{7}$ and $\mathrm{Ca}^{2+}$ codoping was found to be efficient for its suppression. ${ }^{8,9}$ A positive role for $\mathrm{Yb}^{2+}$ ions in afterglow suppression of LSO:Ce was found as well, decreasing it by more than two orders of magnitude, however, at the serious expense of light output. ${ }^{10}$ In CsI:Tl scintillators, the afterglow level was effectively reduced by codoping with $\mathrm{Eu}^{2+}$ and $\mathrm{Sm}^{2+}$ ions. ${ }^{11-14}$ Nevertheless, the atomistic mechanism of $\mathrm{Eu}^{2+}$ and $\mathrm{Sm}^{2+}$ functioning is completely different. Samarium ions introduce a non-radiative recombination channel that decreases the radiative recombination of trapped carriers, ${ }^{14}$ but co-doping with europium introduces deep electron traps scavenging electrons from shallow traps associated with thallium, which results in a slower afterglow. ${ }^{12}$ However, co-doping with these ions seriously deteriorated the light yield in both cases. Recently, Totsuka et al. claimed that using the $\mathrm{Bi}^{3+}$ codoping the afterglow of CsI:Tl can be less than $0.1 \%$ after $10 \mathrm{~ms}$ without a strong decrease of the radioluminescence efficiency under low energy X-ray (less than $30 \mathrm{keV}$ ) excitation. ${ }^{15}$ However, in an attempt to verify this result, we found that the light yield and energy resolution of Bi-codoped CsI:Tl crystals became much worse even for the lowest $\mathrm{Bi}$ concentration of about $0.005 \mathrm{~mol} \%$ (in the melt). ${ }^{16}$

Therefore, despite the success of the afterglow suppression in CsI:Tl the codoping strategies mentioned above have simultaneously deteriorated the other important scintillation characteristics such as light yield and energy resolution which points to the complex character of the scintillation mechanism. Impurities (doped ions) may introduce energy levels in the band gap of the host crystal which interfere with the charge 
carrier migration and relaxation processes: while the afterglow level is dramatically improved, other scintillation properties such as light yield and energy resolution may be seriously degraded.

The search for codopants which can effectively diminish the delayed radiative recombination (afterglow) at $\mathrm{Tl}^{+}$centres and not deleteriously affect other scintillation properties is the primary goal of this work. Due to the electronic structure similarity between $\mathrm{Eu}^{2+}$ and $\mathrm{Yb}^{2+},{ }^{17}$ the afterglow suppression effect by $\mathrm{Yb}^{2+}$ codoping is expected. Thus, in this paper, we study the effects of $\mathrm{Yb}^{2+}$ co-doping on the optical and scintillation properties of CsI:Tl, including afterglow level, light yield, energy resolution, and relative scintillation efficiency.

We used the vertical Bridgman technique to grow two groups of CsI:Tl,Yb crystals. The crystals referred to as group A were used for screening the effect of $\mathrm{Yb}^{2+}$ codoping: CsI:0.078 mol\% $\% \mathrm{Tl}^{+}$(further denoted as IT1), CsI:0.078 mol\% $\mathrm{Tl}^{+}, 0.005 \mathrm{~mol} \% \mathrm{Yb}^{2+}$ (further denoted as IT2) and CsI:0.078 mol\% $\mathrm{Tl}^{+}, 0.05 \mathrm{~mol} \% \mathrm{Yb}^{2+}$ (further denoted as IT3). The other crystals referred to as group B were used to further optimize the conditions: CsI:0.156 mol\% $\mathrm{Tl}^{+}$(further denoted as ST3), CsI:0.156 mol\% $\mathrm{Tl}^{+}, 0.005 \mathrm{~mol} \% \mathrm{Yb}^{2+}$ (further denoted as ST1) and CsI:0.234 mol\% $\mathrm{Tl}^{+}, 0.005 \mathrm{~mol} \% \mathrm{Yb}^{2+}$ (further denoted as ST4). The high-purity CsI ( $5 \mathrm{~N})$, TlI $(4 \mathrm{~N})$ (both from Chemetall), and $\mathrm{YbI}_{2}(5 \mathrm{~N})$ (Aldrich) according to the stoichiometric ratio were loaded in the quartz ampoules and then heated in a vacuum to eliminate the residual humidity. The ampoules were maintained at a temperature of $100{ }^{\circ} \mathrm{C}$ above the melting point of cesium iodide for $24 \mathrm{~h}$ to ensure homogeneity of the melt. Then, ampoules were passed through an optimal temperature gradient with a speed of $0.6 \mathrm{~mm} \mathrm{~h}^{-1}$. The resultant boules were $35 \mathrm{~mm}$ in diameter and $100 \mathrm{~mm}$ in length. All the crystals were transparent and colorless (see inset of Fig. 1). The samples used for dopant concentration measurement were cut at the same position along the boule. The actual dopant concentrations in the crystals were measured by Perkin-Elmer ELAN DRC-e Inductively Coupled Plasma Mass

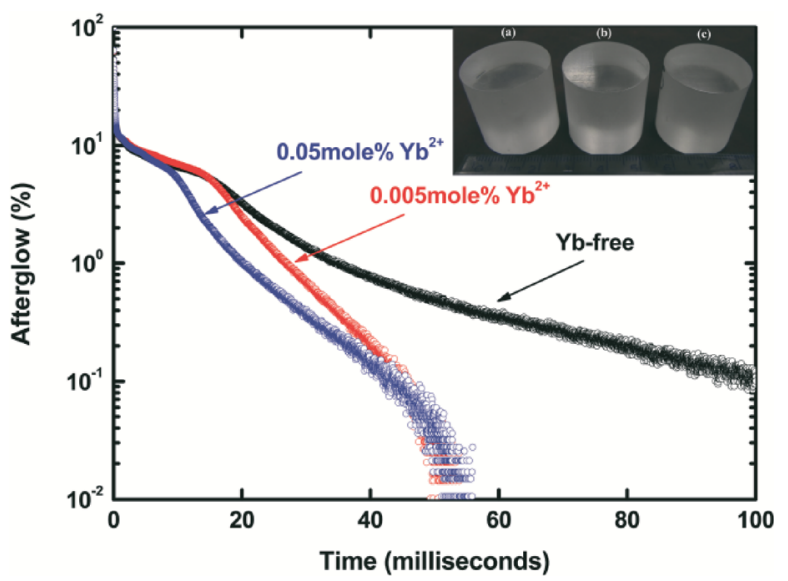

Fig. 1 Afterglow profiles of $\mathrm{Csl}: \mathrm{Tl}^{+}, \mathrm{Yb}^{2+}$ group A crystals after X-ray pulse excitation. Inset shows the photograph of double-faced polished group A crystals with different $\mathrm{Yb}^{2+}$ concentration: none (a), $0.005 \%$ (b), $0.05 \%$ (c).
Spectrometry (ICP-MS). The measured $\mathrm{Tl}^{+}$concentration in crystals are listed in Tables 1 and 2 . Yb concentration was below the sensitivity limit of the apparatus ( $5 \mathrm{ppm}$ ) so that the data are not shown here. All samples were clear and uniform, without any visible inclusions or cracks. Two sample dimensions were chosen for measurements. The first one was $\varnothing 25.4 \times 25.4 \mathrm{~mm}^{3}$ double-faced polished crystals (see inset of Fig. 1). These samples were wrapped in Teflon tapes and used for afterglow, pulse height spectra and X-ray excited luminescence spectra measurements. Before these measurements, all wrapped crystals were stored in the dark for at least $24 \mathrm{~h}$. The second sample dimension was a double-faced polished $5 \times 5 \times 2 \mathrm{~mm}^{3}$ plate used for the rest of measurements.

The afterglow curves were measured by using a singleshot pulse X-ray excitation (pulse duration of $80 \mathrm{~ns}$ ). The afterglow profiles were recorded by using 20000 data points taken from the oscilloscope (Tektronix DPO 5104) using a photomultiplier (PMT) tube detection (R669). The afterglow level $\eta(t)$ was calculated as a ratio between the luminescence intensities $\left(I_{0}\right)$ measured during the X-ray irradiation pulse and at the time delay $(t)$ after the irradiation is terminated, namely $\eta(t)=I(t) / I_{0} \times 100 \%$.

The wrapped cylinder group A crystals for light yield measurement were coupled with a Hamamatsu R878-WT1734 series PMT with no optical grease or other coupling material. The crystals were excited with $662 \mathrm{keV}$ gamma rays from ${ }^{137}$ Cs source located $10 \mathrm{~mm}$ from the crystal surface, and then pulse-height spectra were recorded by a Digbase multichannel spectrometer. The shaping time and PMT high voltage was fixed at $2 \mu \mathrm{s}$ and $1050 \mathrm{~V}$, respectively. The natural background spectrum from the crystal was not subtracted.

The wrapped cylinder group B crystals for absolute light yield and energy resolution measurements were coupled with Hamamatsu R1306 PMT with a bi-alkali photo-cathode and a borosilicate glass window. A collimated ${ }^{22} \mathrm{Na}$ source $(511 \mathrm{keV})$ was used to excite the samples. The photopeak positions were obtained by a simple Gaussian fit. The light output (LO) is measured by single photo-electron peak calibration. The absolute light yield (LY) was calculated using LO, the emission weighted quantum efficiency (EWQE) of the Hamamatsu R1306 PMT at $550 \mathrm{~nm}$ which is of about $5.0 \pm 0.3 \%$, and light collection efficiency (LCE) which is assumed to be 1 . The specific equation LY [photons $\mathrm{MeV}^{-1}$ ] $\approx$ LO [photoelectrons $\left.\mathrm{MeV}^{-1}\right] /($ EWQE $\times$ LCE $)$ was used. Scintillation decay time was measured by the same equipment by tuning the integration time. Scintillation measurements described for group B samples were performed at Prof. Renyuan Zhu's HEP group in California Institute of Technology.

The radioluminescence spectra without calibration were conducted on an X-ray Excited Luminescence Spectrometer, assembled at the Shanghai Institute of Ceramics. The excitation source of this equipment is a medical F30III-2 type mobile diagnostic X-ray machine coupled with the $44 \mathrm{~W}$ plane grating monochromator and Hamamatsu R456 PMT. Optical absorption spectra were recorded on a Varian Cary 5000 spectrophotometer. Photoluminescence decay profiles were recorded 
Table 1 Luminescence and scintillation characteristics of $\mathrm{Csl}: \mathrm{Tl}^{+}, \mathrm{Yb}^{2+}$ group A crystals

\begin{tabular}{|c|c|c|c|c|c|c|c|c|}
\hline & T1 conc & tion $(\mathrm{mol} \%)$ & \multirow{2}{*}{$\begin{array}{l}\text { Yb concentration } \\
(\mathrm{mol} \%) \text { In melt }\end{array}$} & \multirow{2}{*}{$\begin{array}{l}\text { PL decay } \\
\text { constant }^{a}(\mathrm{~ns})\end{array}$} & \multirow{2}{*}{$\begin{array}{l}\text { Afterglow level } \\
\text { @ } 50 \mathrm{~ms}(\%)\end{array}$} & \multirow{2}{*}{$\begin{array}{l}\text { Relative light } \\
\text { yield }^{b}(\%)\end{array}$} & \multirow{2}{*}{$\begin{array}{l}\text { RL integral } \\
\text { intensity }^{c}(\%)\end{array}$} & \multirow{2}{*}{$\begin{array}{l}\text { RL relat. intensity } \\
\text { at } 400 \mathrm{~nm}^{d}(\%)\end{array}$} \\
\hline Sample & In melt & In crystal & & & & & & \\
\hline IT1 & 0.078 & 0.010 & 0 & 540 & 0.490 & 100 & 100 & 18.6 \\
\hline IT3 & 0.078 & 0.012 & 0.05 & 543 & 0.041 & 86 & 76 & 8 \\
\hline
\end{tabular}

${ }^{a}$ Monitoring at $\lambda_{\mathrm{ex}}=322 \mathrm{~nm}$ and $\lambda_{\mathrm{em}}=520 \mathrm{~nm} .{ }^{b}$ Measured from the energy spectra under ${ }^{137} \mathrm{Cs}$ excitation. ${ }^{c}$ Measured from the data of X-ray excited luminescence spectra. ${ }^{d}$ RL intensity at the spectrum maximum is defined as $100 \%$.

Table 2 Scintillation characteristics comparison between $\mathrm{Csl}: \mathrm{Tl}^{+}, \mathrm{Yb}^{2+}$ (group B) and $\mathrm{Srl}_{2}: \mathrm{Eu}^{2+}$ single crystals with the identical size

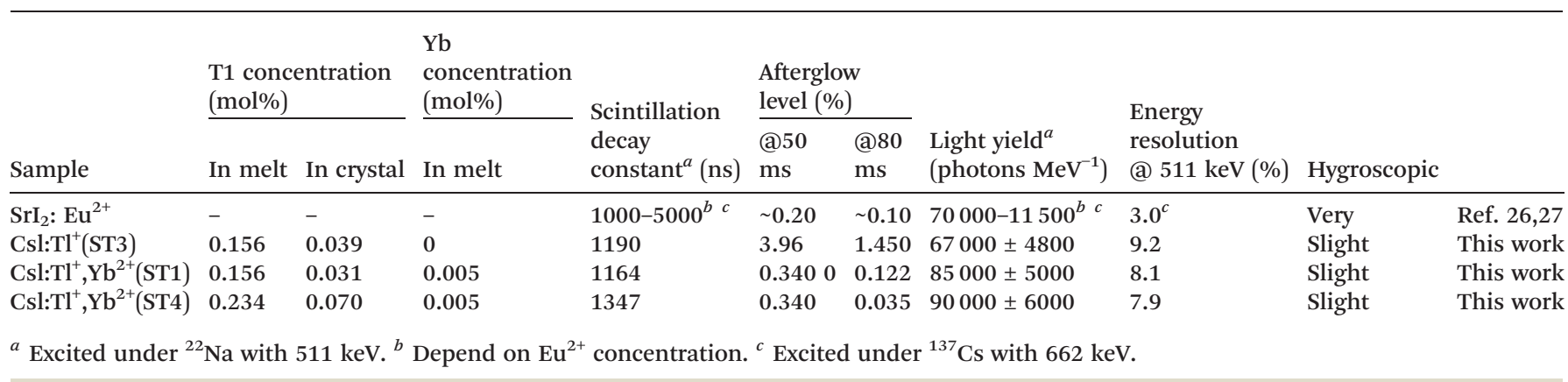

on Edinburgh FLS920 fluorescence spectrometer, respectively. All the above described measurements were performed at room temperature.

Fig. 1 presents the results of afterglow measurements performed for the group A crystals. The afterglow level of the $\mathrm{Yb}^{2+}$ codoped ones decrease by more than one order of magnitude in comparison with the $\mathrm{Yb}^{2+}$-free one after $50 \mathrm{~ms}$. Compared with the $\mathrm{Eu}^{2+}, \mathrm{Sm}^{2+}$ or $\mathrm{Bi}^{3+}$ codopants mentioned above the performance of $\mathrm{Yb}^{2+}$ codopant is comparable as it lowers the afterglow level down to $0.041 \%$ in comparison with $0.03 \%$ for $\mathrm{Bi}^{3+},{ }^{15} \sim 0.03 \%$ for $\mathrm{Eu}^{2+}$ codopant, ${ }^{11}$ and $\sim 0.1 \%$ for $\mathrm{Sm}^{2+} .{ }^{13}$

The emission spectra under steady-state X-ray excitation of group A crystals were measured (see ESI $\dagger$ ). In the Yb-doped samples the emission spectrum exhibits a similar pattern to that of the Yb-free one. ${ }^{11}$ After normalization, an interesting phenomenon was noticed: a gradual decrease of relative intensity of the shoulder at $400 \mathrm{~nm}$ with increasing $\mathrm{Yb}^{2+}$ concentration compared to maximum of the spectrum around $500 \mathrm{~nm}$ (defined as $100 \%$ ) clearly occurs, see Table 1 . Integrating the radioluminescence spectra, the relative scintillation efficiency can be compared among the samples. The decreasing trend in Yb-doped samples is obvious and relative reduction is larger than that of relative light yield, see Table 1 . Because the emission under steady-state X-ray excitation (scintillation efficiency) includes both the fast scintillation component (measured in light yield) and the slower (delayed) components responsible for the afterglow, it means that the $\mathrm{Yb}^{2+}$ codoping is reducing the unwanted slower components. For CsI:Tl, the unwanted slower components (afterglow emission) were ascribed to the delayed Tl-related band peaking at about $560 \mathrm{~nm}^{18}$ and $400 \mathrm{~nm} .{ }^{19}$ Due to the strong decrease of the quantum efficiency of the
PMT above $500 \mathrm{~nm}$, the true maximum of the emission at 550-560 nm cannot be observed in our uncorrected spectra. In our spectra, the maximum of this emission peaks at $500 \mathrm{~nm}$. The cause for the relative decrease of the $400 \mathrm{~nm}$ shoulder in the emission spectra of Yb-codoped samples will be discussed in the following paragraph. The photoluminescence decay times of $\mathrm{CsI}: \mathrm{Tl}^{+}, \mathrm{Yb}^{2+}$ crystals are also shown in Table 1. All samples exhibited similar values of about 540 ns, slightly shorter than $585 \mathrm{~ns}$ reported in ref. 20, which proves no negative effects coming from $\mathrm{Yb}$ codoping on the $\mathrm{Tl}^{+}$emission centers themselves. The photopeaks in pulse-height spectra were approximated by a Gaussian to evaluate the peak position and to estimate the relative light yield (see ESI $\dagger$ ) of group A crystals. Relative light yield values under the $662 \mathrm{keV}$ gamma excitation from ${ }^{137} \mathrm{Cs}$ are also listed in Table 1. At the lowest Yb co-doping concentration ( $0.005 \mathrm{~mol} \%)$, the light yield shows approximately $2 \%$ loss compared to Yb-free CsI:Tl. For higher co-doping concentration of $0.05 \mathrm{~mol} \%$, the light yield loss is about $14 \%$.

After further optimization of $\mathrm{Tl}^{+}$and $\mathrm{Yb}^{2+}$ concentrations, a composition with excellent scintillation performance was obtained. Pulse height spectra of optimized group B crystals under ${ }^{22} \mathrm{Na}$ (511 keV) excitation were measured. The light outputs as a function of integration time for group B are shown in Fig. 2. When the integration time was $4 \mu \mathrm{s}$, the light output for ST3, ST1 and ST4 was 3350, 4241, and 4510 p.e. $\mathrm{MeV}^{-1}$, respectively. Considering the EWQE of R1306 PMT at $550 \mathrm{~nm}$ the emission maximum of $\mathrm{CsI}_{\mathrm{Tl}}^{+}, \mathrm{Yb}^{2+}$ and $\mathrm{LCE}$, it is estimated that the light yield of the best Yb-codoped crystal (ST4) can reach $90000 \pm 6000$ photons $\mathrm{MeV}^{-1}$. The light yield of ST1 sample was $85000 \pm 5000$ photons $\mathrm{MeV}^{-1}$, which is still much higher than that of the Yb-free one (ST3) which was 


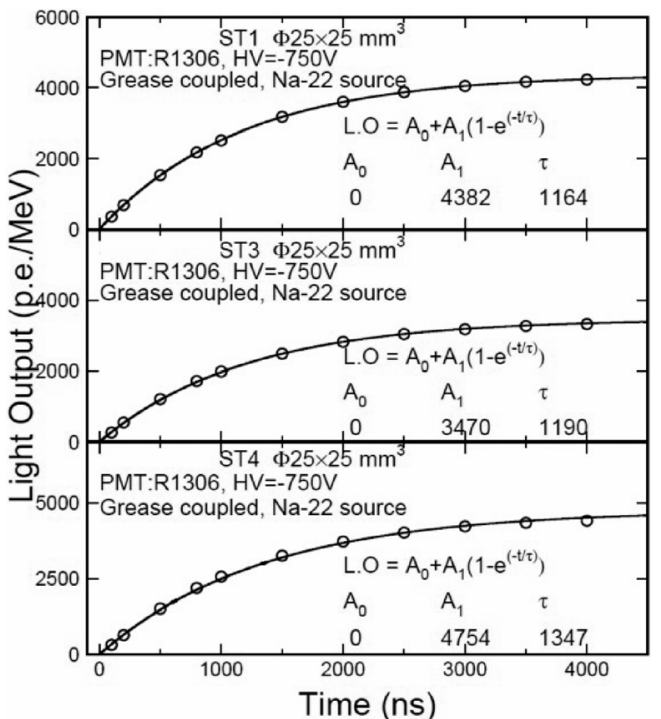

Fig. 2 Light output as a function of integration time for $\mathrm{Csl}: \mathrm{Tl}^{+}, \mathrm{Yb}^{2+}$ group B crystals.

$67000 \pm 4800$ photons $\mathrm{MeV}^{-1}$, close to the typical value of 65000 photons $\mathrm{MeV}^{-1}$ for CsI:Tl single crystal. ${ }^{2,21,22}$ On the basis of the Bartram-Lempicki model $L_{\mathrm{R}}=10^{6} /\left(\beta \times E_{\mathrm{g}}\right),{ }^{23}$ the number of photons per unit of absorbed energy $(\mathrm{MeV})$ can be roughly estimated, where $E_{\mathrm{g}}=6.2 \mathrm{eV}^{24}$ is the bandgap of CsI, the value of $\beta$ is $1.5-1.8^{25}$ for ionic halide compounds. Thus, the theoretical light yield $L_{\mathrm{R}}$ for CsI:Tl should be within 89600-107500 photons $\mathrm{MeV}^{-1}$. It is evident that the light yield of the optimized $\mathrm{CsI}_{\mathrm{Tl}} \mathrm{Tl}^{+} \mathrm{Yb}^{2+}$ approaches its theoretical value. The reasons for the light yield improvement are not understood at this stage, and further experimental investigation is currently ongoing. The pulse height spectra of optimized $\mathrm{CsI} \mathrm{Tl}^{+}, \mathrm{Yb}^{2+}$ crystals (group B) under ${ }^{22} \mathrm{Na}$ excitation are presented in Fig. 3. The FWHM energy resolutions obtained for $511 \mathrm{keV} \gamma$-rays from the ${ }^{22} \mathrm{Na}$ source are $9.2 \%, 8.1 \%$ and $7.9 \%$ for ST3, ST1 and ST4, respectively, plotted in Fig. 3. Besides, its scintillation decay time is about $1.3 \mu \mathrm{s}$, close to $1.2 \mu \mathrm{s}$ of the Yb-free one (see Table 2).

Fig. 4 shows the afterglow profiles after the X-ray pulse excitation. It is found that the Yb-doped crystal with highest light yield value exhibits the lowest afterglow level of about $0.035 \%$ at $80 \mathrm{~ms}$ while the $\mathrm{Yb}$-free sample shows about $1.14 \%$ (see Table 2). Thus, simultaneous improvement of afterglow, light yield and energy resolution in the Yb-codoped CsI:Tl scintillator, reported for the first time, will pave the way to its application in fast imaging techniques. We also note that, except for the energy resolution, in the case of identical size the physical and other scintillation performances of slightly hygroscopic $\mathrm{CsI}^{\mathrm{Tl}}{ }^{+}, \mathrm{Yb}^{2+}$ crystals are comparable to those of the ultra-efficient (quite hygroscopic) alkali earth iodide scintillator - $\mathrm{SrI}_{2}: \mathrm{Eu}^{2+}$, see comparison in Table 2.

Fig. 5 presents the optical absorption spectra of group B crystals in the range of $300-800 \mathrm{~nm}$. The abrupt absorbance increase below $330 \mathrm{~nm}$ is due to the onset of A-absorption band of $\mathrm{Tl}^{+}$center, ${ }^{28}$ and there is no additional absorption

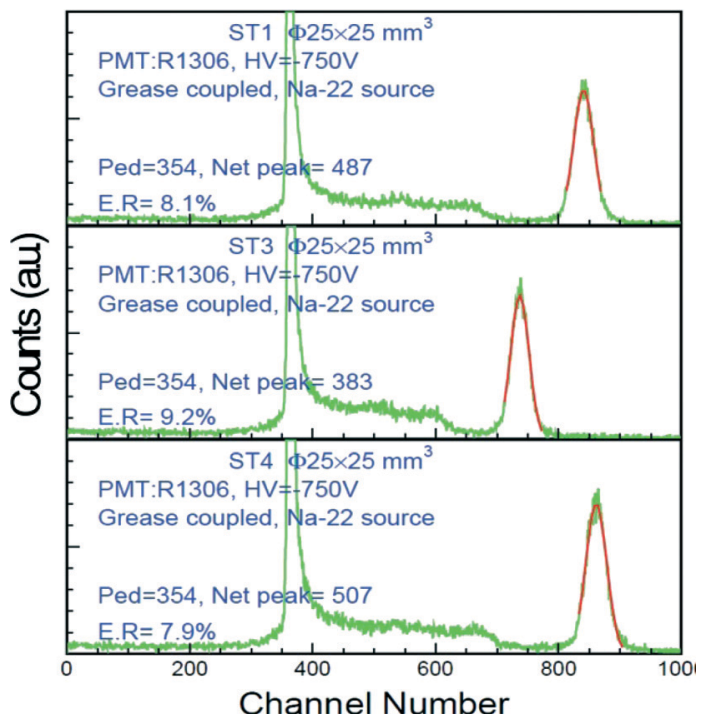

Fig. 3 Pulse height spectra of optimized $\mathrm{Csl}: \mathrm{Tl}^{+}, \mathrm{Yb}^{2+}$ group B crystals coupled with Hamamatsu R1306 PMT under ${ }^{22} \mathrm{Na}$ excitation. Spectra start at channel no. 354, net photopeak position is marked in the figure, and the solid red line is the Gaussian approximation of photopeak. The "net peak" equals the measured peak after subtracting the ADC pedestal signal. The equation, energy resolution (E.R.) = FWHM/Channel of "net peak", is used to determine the energy resolution.

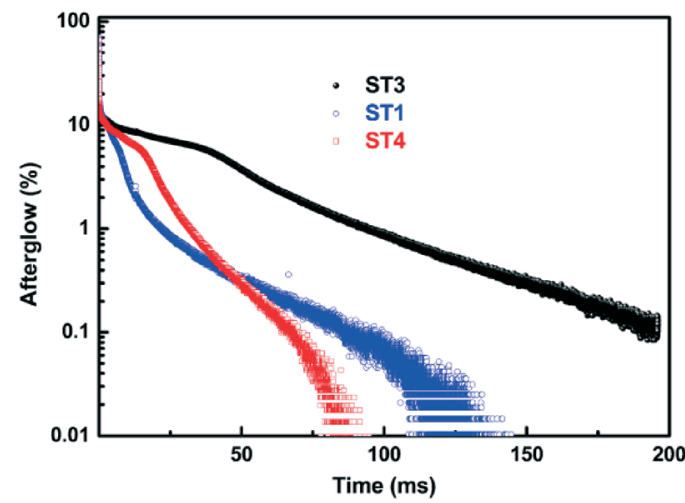

Fig. 4 Afterglow profiles of $\mathrm{Csl}: \mathrm{Tl}^{+}, \mathrm{Yb}^{2+}$ group B crystals after X-ray pulse excitation.

band induced by $\mathrm{Yb}$ codoping, unlike in the case of $\mathrm{Bi}^{3+}$ codoping. ${ }^{15,16}$ An absence of the absorption features of the allowed $\mathrm{Yb}^{3+}$ related charge transfer (CT) transition, which should occur within $500-600 \mathrm{~nm}$ in iodides, ${ }^{29}$ implies that only the $\mathrm{Yb}^{2+}$ ions are stable in CsI host, which is also natural from the point of view of their charge compared to $\mathrm{Cs}^{+}$. The lowest $4 \mathrm{f}-5 \mathrm{~d}_{1}$ transition of $\mathrm{Yb}^{2+}$ should be situated around $400-420 \mathrm{~nm}$ in the CsI host taking into account the similarity of $4 \mathrm{f}-5 \mathrm{~d}$ transition positioning for $\mathrm{Yb}^{2+}$ and $\mathrm{Eu}^{2+17}$ and the position of $\mathrm{Eu}^{2+} 4 \mathrm{f}-5 \mathrm{~d}_{1}$ absorption band in CsI. ${ }^{30}$ However, due to the strongly spin forbidden character of $4 \mathrm{f}-5 \mathrm{~d}$ transition in $\mathrm{Yb}^{2+}$ it can be hardly observed in this concentration range. ${ }^{31}$ Besides, in the $\mathrm{Yb}^{2+}$ codoped crystals, the apparent shift of $\mathrm{Tl}^{+}$absorption edge in the codoped crystal was observed (inset of Fig. 5). We also recall the relative decrease 


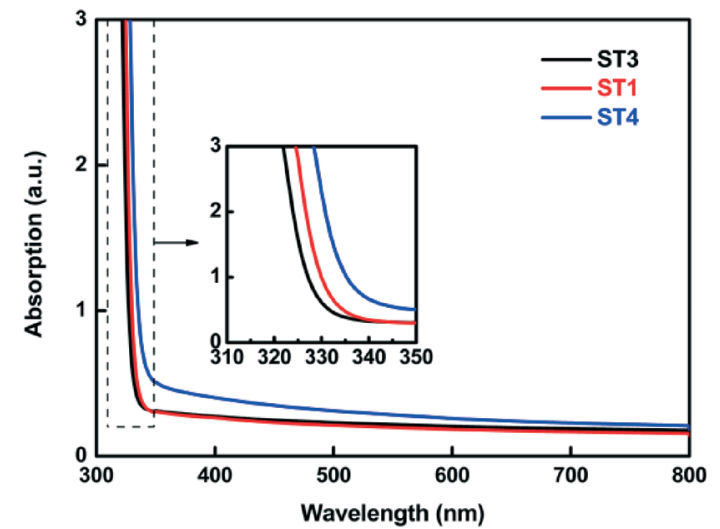

Fig. 5 Optical absorption spectra of optimized $\mathrm{Csl} \mathrm{Tl}^{+}, \mathrm{Yb}^{2+}$ group B crystals. Parts of the spectra were enlarged for clear observation.

of the $400 \mathrm{~nm}$ shoulder in the emission spectra of Yb-codoped samples (Table 1) which can be due to nonradiative energy transfer from the $\mathrm{Tl}^{+}$-like $400 \mathrm{~nm}$ band towards $\mathrm{Yb}^{2+} 4 \mathrm{f}-5 \mathrm{~d}_{1}$ absorption band or due to the change of the energy barrier for thermally stimulated transition from the $400 \mathrm{~nm}$ band towards the other co-existing exciton-like minima on the common adiabatic potential surface of the emission center excited state. ${ }^{32}$ The observed changes in the absorption and emission characteristics of $\mathrm{Tl}^{+}$centers in the $\mathrm{Yb}$-codoped crystals point to the spatial correlation between the $\mathrm{Yb}^{2+}$ and $\mathrm{Tl}^{+}$ centers. In such a case the delayed migrating holes can be inhibited to reach $\mathrm{Tl}^{0}$ being captured at $\mathrm{Yb}^{2+}$ ion in the vicinity. The return of the $\mathrm{Yb}^{3+}+\mathrm{Tl}^{0}$ excited ion couple to the ground state can be easily nonradiative taking into account the wellknown case of $\mathrm{Ce}^{3+}$ emission quenching in the $\mathrm{Ce}^{4+}$ and $\mathrm{Yb}^{2+}$ pairs e.g. in garnet ${ }^{33}$ or oxyorthosilicate ${ }^{34}$ materials.

\section{Conclusions}

In summary, a positive role of $\mathrm{Yb}^{2+}$ codoping in the afterglow suppression in CsI:Tl crystals was found. In the optimized composition, the $\mathrm{CsI}: \mathrm{Tl}^{+}, \mathrm{Yb}^{2+}$ crystal has so far exhibited an ultra-high light yield value of $90000 \pm 6000$ photons $\mathrm{MeV}^{-1}$, energy resolution 7.9\%@511 keV and suppressed afterglow level down to $0.035 \%$ at $80 \mathrm{~ms}$. Simultaneous improvement of the afterglow level, light yield and energy resolution in the Yb-codoped CsI:Tl scintillator compared to the standard CsI:Tl one is considered as a breakthrough in the optimization of the scintillator and paves the way for its application in X-ray fast imaging applications. The afterglow suppression in CsI: $\mathrm{Tl}^{+}, \mathrm{Yb}^{2+}$ crystal is explained by spatial correlation of $\mathrm{Yb}^{2+}$ and $\mathrm{Tl}^{+}$ions where the former can trap the delayed migrating holes and inhibit their radiative recombination with $\mathrm{Tl}^{0}$ counterpart.

\section{Acknowledgements}

This work was supported by the National Natural Science Foundation of China (grant no. 51372256) and State Key
Laboratory of Rare Earth Resources Utilization (Grant No. RERU2014013). Partial support of the project of Sino-Czech collaboration funded by MEYS (Czech side), KONTAKT II, no. 12185 is also gratefully acknowledged.

\section{Notes and references}

1 W. Van Sciver and R. Hofstadter, Phys. Rev., 1951, 84, 1062.

2 M. Nikl, Meas. Sci. Technol., 2006, 17, R37.

3 B. K. Cha, J. H. Bae, C. H. Lee, S. H. Chang and G. Cho, Nucl. Instrum. Methods Phys. Res., Sect. A, 2011, 633, S297.

4 L. A. Kappers, R. H. Bartram, D. S. Hamilton, C. Brecher, A. Lempicki, V. Gaysinskiy, E. E. Ovechkina and V. V. Nagarkar, Radiat. Meas., 2007, 42, 537.

5 J. H. Siewerdsen and D. A. Jaffray, Med. Phys., 1999, $26,8$.

6 S. C. Thacker, B. Singh, V. Gaysinskiy, E. E. Ovechkina, S. R. Miller, C. Brecher and V. V. Nagarkar, Nucl. Instrum. Methods Phys. Res., Sect. A, 2009, 604, 89.

7 P. Dorenbos, J. Phys.: Condens. Matter, 1994, 6, 4167.

8 K. Yang, C. L. Melcher, P. D. Rack and L. A. Eriksson, IEEE Trans. Nucl. Sci., 2009, 56, 2960.

9 J. J. Zhu, M. Gu, X. L. Liu, B. Liu, S. M. Huang and C. Ni, J. Lumin., 2013, 139, 1.

10 N. G. Starzhinskiy, O. Sidletskiy, G. Tamulaitis, K. A. Katrunov, I. M. Zenya, Y. V. Malyukin, O. V. Viagin, A. A. Masalov and I. A. Rybalko, IEEE Trans. Nucl. Sci., 2013, 60(2), 1427.

11 C. Brecher, A. Lempicki, S. R. Miller, J. Glodo, E. E. Ovechkina, V. Gaysinskiy, V. V. Nagarkar and R. H. Bartram, Nucl. Instrum. Methods Phys. Res., Sect. A, 2006, 558, 450.

12 R. H. Bartram, L. A. Kappers, D. S. Hamilton, A. Lempicki, C. Brecher, J. Glodo, V. Gaysinskiy and E. E. Ovechkina, Nucl. Instrum. Methods Phys. Res., Sect. A, 2006, 558, 458.

13 V. V. Nagarkar, C. Brecher, E. E. Ovechkina, V. Gaysinskiy, S. R. Miller, S. Thacker, A. Lempicki and R. H. Bartram, IEEE Trans. Nucl. Sci., 2008, 55(3), 1270.

14 L. A. Kappers, R. H. Bartram, D. S. Hamilton, A. Lempicki, C. Brecher, V. Gaysinskiy, E. E. Ovechkina, S. Thacker and V. V. Nagarkar, Radiat. Meas., 2010, 45, 426.

15 D. Totsuka, T. Yanagida, Y. Fujimoto, Y. Yokota, F. Moretti, A. Vedda and A. Yoshikawa, Appl. Phys. Express, 2012, $5,052601$.

16 Y. T. Wu, G. H. Ren, X. F. Chen, D. Z. Ding, H. Y. Li and S. K. Pan, Submitted.

17 P. Dorenbos, J. Phys.: Condens. Matter, 2003, 15, 8417.

18 J. M. Spaeth, W. Msise and K. S. Song, J. Phys.: Condens. Matter, 1994, 6, 3999.

19 C. Brecher, V. V. Nagarkar, V. Gaysinskiy, S. R. Miller and A. Lempicki, Nucl. Instrum. Methods Phys. Res., Sect. A, 2005, 537, 117.

20 M. M. Hamada, F. E. Costa, C. C. Pereira and S. Kubota, IEEE Trans. Nucl. Sci., 2001, 48(4), 1148.

21 M. J. Weber, J. Lumin., 2002, 100(1-4), 35.

22 C. W. E. Eijk, Nucl. Instrum. Methods Phys. Res., Sect. A, 2003, 509, 17.

23 A. M. Srivastava and C. R. Ronda, Luminescence: Theory and Applications, Wiley-VCH: Weinheim, Germany, ch 52007. 
24 S. L. Molodtsov, A. Puschmann, C. Laubschat, G. Kaindl and V. K. Adamchuk, Phys. Rev. B: Condens. Matter, 1991, 44(3), 1333.

25 P. A. Rodnyi, P. Dorenbos and C. W. E. van Eijk, Phys. Status Solidi B, 1995, 187, 15.

26 R. Hawrami, J. Glodo, K. S. Shah, N. Cherepy, S. Payne, A. Burger and L. Boatner, J. Cryst. Growth, 2013, 379, 69.

27 E. V. van Loef, K. S. Shah, J. Glodo and G. M. Wilson, US patent: US2010/0268074 A1, 2010.

28 S. Masunaga, I. Morita and M. Ishiguro, J. Phys. Soc. Jpn., 1966, 21, 638.

29 M. Nikl, A. Yoshikawa and T. Fukuda, Opt. Mater., 2004, 26,545 .
30 H. J. Seo, W. S. Zhang, T. Tsuboi, S. H. Doh, W. G. Lee, H. D. Kang and K. W. Jang, J. Alloys Compd., 2002, 344, 268.

31 A. Bensalah, M. Nikl, E. Mihokova, N. Solovieva, A. Vedda, H. Sato, T. Fukuda and G. Boulon, Radiat. Meas., 2004, $38,545$.

32 V. Nagirnyi, A. Stolovich, S. Zazubovich, V. Zepelin, E. Mihokova, M. Nikl, G. P. Pazzi and L. Salvini, J. Phys.: Condens. Matter, 1995, 7, 3637.

33 N. Guerassimova, N. Garinier, C. Dujardin, A. G. Petrosyan and C. Pedrini, Chem. Phys. Lett., 2001, 339(3-4), 197.

34 D. W. Cooke, R. E. Muenchausen, B. L. Bennett, K. J. McClellan and A. M. Portis, J. Lumin., 1998, 79(3), 185. 